\title{
Semicultura e educação: uma análise crítica da revista Nova Escola
}

\author{
Sinésio Ferraz Bueno \\ Universidade Estadual Paulista - Campus Marília, Departamento de Filosofia
}

Durante o exílio nos Estados Unidos, o filósofo alemão Theodor W. Adorno dedicou-se a pesquisar os apelos dirigidos pela indústria cultural a seus consumidores, especialmente no campo da música. Esse pensador voltou-se igualmente para a pesquisa da manipulação da subjetividade exercida pela indústria cultural também em outros campos, e esse é o caso de sua análise da coluna astrológica do jornal Los Angeles Times, entre 1952 e 1953. Partindo do evidente anacronismo da existência de colunas astrológicas em um mundo secularizado, Adorno procurou compreender as necessidades inconscientes que levam os indivíduos à consulta do horóscopo. Tais necessidades se mostraram condizentes com o perfil da personalidade autoritária, definidas durante o célebre estudo dos frankfurtianos junto à população norte-americana na década de 1940. Assim como na pesquisa sobre o horóscopo, o ponto de partida da pesquisa sobre a personalidade autoritária, ou fascista, foi a existência de um tipo humano que combina comportamentos secularizados do mundo moderno a tendências irracionais de pensamento, típicos de sociedades anteriores à era moderna. Por meio de questionários e en- trevistas clínicas, uma equipe de trabalho formada por filósofos, sociólogos e psicanalistas elaborou a "Escala F", indicador empírico por meio do qual se buscou aferir o potencial fascista dos indivíduos em uma sociedade de massas. Partiu-se do pressuposto de que isso poderia ser possível por meio de indagações indiretas acerca de questões como anti-semitismo, racismo, etnocentrismo e conservadorismo social e político. Segundo Adorno, o fascista em potencial, ou seja, o tipo psicológico radicado nos níveis mais elevados da Escala F, caracteriza-se pela tendência irracional de identificação com grupos sociais superiores, sentimento complementado pelo realismo exagerado, entendendo-se essa segunda característica não como uma busca de compreensão do mundo pela razão, mas como a tendência de reconhecer a superioridade absoluta da realidade ante o indivíduo. $\mathrm{O}$ realismo da personalidade autoritária é, sobretudo, antiutópico, implicando a absoluta submissão diante do existente. Para o fascista em potencial, cada indivíduo não tem outra escolha que não seja submeter-se "a uma adaptação que implica resignação perante a impossibilidade de lograr qualquer melhora essencial, que te- 
mos de abandonar todo sonho e nos moldarmos até nos convertermos em um acessório a mais da máquina social" (Adorno, 1965, p. 650).

Analogamente, o conteúdo da coluna astrológica do Los Angeles Times revelou a presença das mesmas necessidades subjetivas que se mostraram latentes na personalidade autoritária. Segundo Adorno, a consulta aos astros reflete a dependência e impotência dos indivíduos em uma sociedade de massas diante do aparato econômico. A aceitação inflexível dos imperativos de uma totalidade repressiva, que a todos é cobrada como condição para a socialização, é mascarada nas consciências por meio da idéia confortadora de que tal submissão ocorreria ante a ordem cosmológica inalcançável. Os conselhos astrológicos, cumprindo uma função entorpecedora, permitem que os poderes objetivos, que efetivamente submetem os indivíduos, sejam elevados a uma esfera situada acima da conduta e da psicologia individuais, subtraídos a toda crítica, revestidos de dignidade metafísica duvidosa. Por meio de apelos ao superego de cada um, o astrólogo atua como agente da totalidade, atendendo a necessidades regressivas criadas por essa mesma totalidade, que, assim, se torna imune à crítica.

E o convite constante a criticar-se a si mesmo, e não às condições dadas, corresponde a um aspecto do conformismo social, em cujo megafone se converte, definitivamente, o horóscopo; pois se as notas individuais por este produzidas não deixam de apontar, mesmo que palidamente, a uma totalidade defeituosa, seus conselhos procuram sem demora remendar de novo o existente. (Adorno, 1965, p. 209)

Com engenhosidade, o astrólogo reduz as contradições econômicas e sociais a denominadores comuns que as convertem em dicotomias naturais supostamente regidas pelos astros, como a oposição entre trabalho e ócio ou entre vida pública e vida privada. As contradições objetivas, uma vez subtraídas da dimensão material, são reduzidas a oposições atribuídas à esfera natural, de maneira que possam ser reconciliadas. $\mathrm{O}$ estado objetivo de coisificação é rei- terado, por meio de locuções e estereotipias rígidas, traduzidas em conhecidos conselhos sobre a necessidade de sobriedade nos gastos pessoais, cuidados com a saúde, a esperança da ajuda inesperada de um amigo ou do sucesso na vida amorosa. Sobretudo, é da vida fetichizada de cada um que se fala, mas os fetiches reais, deslocados para um plano transcendente, tornam essa vida menos duramente suportável.

Em resumo, podemos afirmar que a análise da coluna astrológica feita por Adorno nos revela os motivos do prestígio paradoxal de apelos claramente falsos e anacrônicos no mundo contemporâneo. Pelo horóscopo, os indivíduos satisfazem necessidades regressivas típicas da personalidade autoritária: a identificação com o status quo, a submissão ao sistema capitalista e a explicação dos motivos que podem levar ao sucesso, ou, mais comumente, ao fracasso na hierarquia social, como um problema exclusivamente individual, não condicionado pela hierarquia social. A coluna astrológica aparece, assim, como um ícone representativo da forma pela qual a indústria cultural reitera, exaustivamente, pelas mais diversas estereotipias, a mesma mensagem essencial, para a qual as consciências semiformadas foram severamente treinadas: o apelo para que aceitem inflexivelmente a totalidade como se fosse um dado da natureza. As estereotipias astrológicas são construídas mediante um vocabulário operacional que o filósofo alemão Marcuse caracteriza como marca da linguagem no mundo unidimensional. Procura-se fazer do indivíduo e do seu comportamento termos inteiramente ajustáveis e em condição de harmonia com o existente, prevenindo toda crítica conceitual aos fatos sociais. Na verdade, a crença sobre a veracidade das locuções não é o aspecto decisivo: "o novo toque da linguagem mágicoritual é, antes, o de as pessoas não acreditarem nela, ou não se importarem com ela, mas não obstante, agirem em concordância com ela" (Marcuse, 1969, p. 107).

No interior do pensamento de Adorno, um outro caminho que nos conduz à compreensão e crítica do ajustamento social alienado consiste na análise da decadência dos processos formadores da cultura em 
sua caricatura unidimensionalizada, denominada por Adorno como semiformação, ou semicultura. Esse processo de declínio cultural, acelerado nas primeiras décadas do século $\mathrm{XX}$, pode ser compreendido a partir de suas duas faces complementares.

1) Pelo processo de espiritualização da cultura burguesa, por meio do qual os conteúdos críticos, negativos e emancipadores da cultura burguesa foram neutralizados em seu potencial de negação, convertidos em mero "valor" espiritual (Horkheimer \& Adorno, 1971, p. 235).

2) Destituída das qualidades transcendentes inseparáveis da formação, a cultura pôde então ser instrumentalizada como meio de entretenimento, predicado explorado de maneira muito eficiente pela indústria cultural na administração do tempo de lazer dos indivíduos. A massificação da semicultura pela indústria cultural acarretou a homogeneização da cultura entre as classes sociais. Pois, enquanto as elites burguesas têm o tempo ocioso ocupado com valores culturais que testemunham a própria impotência da cultura, aos proletários restou a passagem direta de uma forma de heteronomia a outra, com a substituição da autoridade da Bíblia pelos fetiches da indústria cultural. Como consequiência, a incultura original, que ainda guardava a possibilidade de superação, é substituída por conteúdos massificados que, embora sejam caricatura da formação, se apresentam em seu nome (idem, p. 240-241). Seja para as elites burguesas freqüentadoras de espetáculos nos salões de ópera e exposições nos museus, seja para os proletários, em seu acesso à programação televisiva e cinematográfica, "no clima da semiformação, os conteúdos objetivos, coisificados e com caráter de mercadoria da formação cultural, sobrevivem à custa de seu conteúdo de verdade e de suas relações vivas com o sujeito vivo" (idem, p. 245). Para burgueses e trabalhadores o sonho socialista da igualdade social realiza-se de maneira pervertida, na medida em que ambas as classes sociais são privadas dos veículos culturais que permitiriam a crítica negativa. A unidimensionalização da cultura revela o aspecto mais nefasto da semiformação, vale dizer, sua propriedade de não ser, como muitos pretendem, uma iniciação à formação, mas seu inimigo mortal (idem, p. 255).

A análise adorniana da semiformação apresenta um aspecto central que remete diretamente às modalidades regressivas da personalidade autoritária: "a semicultura é a esfera do ressentimento" (idem, p. 261). Se no capitalismo tardio a lei do mais forte repercute internamente por meio dos traços da personalidade autoritária - a saber, antiintelectualismo, convencionalismo, identificação com as elites econômicas e presença de fortes tendências destrutivas inconscientes -, o modelo fascista e semiformado de personalidade, em vez de canalizar sua hostilidade inconsciente contra as estruturas sociais que a geraram, o que poderia viabilizar a crítica negativa da realidade, o faz contra a própria cultura: "a raiva se voltou contra a própria promessa ela mesma, expressando-se na forma fatal de que essa promessa não deveria existir" (Adorno, 1995, p. 164). Isso aponta o núcleo da personalidade autoritária: o sadomasoquismo.

A caracterização adorniana da semicultura como esfera do ressentimento remete, em termos freudianos, aos elementos anticivilizatórios da própria civilização, que convertem cada ser civilizado em um inimigo potencial da sociedade que o gerou. Esse tema, que é recorrente nos escritos dos filósofos da teoria crítica, recebe de Adorno uma abordagem especialmente valiosa para nossas reflexões no artigo "Sobre música popular", escrito em parceria com George Simpson, em 1941. Esse artigo procede de maneira similar àquele sobre a coluna astrológica, pois analisa os recursos utilizados pelos produtores musicais da indústria cultural para darem conta daquilo que pode ser nomeado a "quadratura do círculo" nessa área, a saber: induzir o público a aceitar com grande entusiasmo um material cultural padronizado, como se a opção por esta ou aquela produção fosse resultado da livre escolha e correspondesse genuinamente aos desejos espontâneos do público. Adorno e Simpson desvendam a solução para esse problema resumindo-a em uma fórmula cuja concisão permanece válida para os ouvidos globalizados de nossos dias: "a composição escuta pelo ouvinte" (Adorno, 
1986, p. 121). Ao contrário da "boa música séria", que possui uma estrutura irredutível a padrões estereotipados, a música popular é submetida a uma estandardização estrutural que induz a uma audição igualmente estandardizada. Para os autores, a música popular apresenta-se "pré-digerida", dispensando o ouvinte de esforços para seguir o fluxo musical, ao mesmo tempo em que lhe fornece modelos sob os quais qualquer outra obra similar poderá ser subsumida. A música popular promove certo automatismo musical que reduz os detalhes das obras a meras engrenagens de uma máquina, de tal maneira que o "detalhe musical impedido de desenvolver-se torna-se uma caricatura de suas próprias potencialidades" (Adorno, 1986, p. 119). Simultaneamente, a estandardização é complementada pela "pseudo-individualização", procedimento que envolve os produtos da indústria cultural com a aparência da livre escolha, induzindo seus consumidores a perceber a escolha e a fruição da obra como resultado da autonomia individual. Esse procedimento é exemplificado pelos autores com a "improvização normatizada" característica do jazz. Esse ritmo, assim como os produtos da indústria cultural em geral, trazem a marca da "quadratura do círculo" na seguinte forma: "a estandardização de hits musicais mantém os usuários enquadrados. Por assim dizer escutando por eles. A pseudoindividuação, por sua vez, os mantém enquadrados, fazendo-os esquecer que o que eles escutam já é sempre escutado por eles, "pré-digerido"' (idem, p. 123).

Essa condição de heteronomia não é, contudo, meramente gerada de cima para baixo, uma vez que a padronização e falsificação da cultura, ao permitir a integração à totalidade repressiva, provoca a neutralização da angústia representada pela não-integração. No capitalismo tardio, a angústia primitiva experimentada pelo homem diante dos poderes da natureza, que o ameaçavam com o perigo da aniquilação física, é perpetuada pelo temor da não-integração nos grupos sociais (Adorno, 1991, p. 143-144). Segundo Adorno, a adesão dos indivíduos aos produtos de qualidade claramente questionável da indústria cultural é impulsionada pelo desespero perante a impossibili- dade de uma adesão racional à sociedade, condição heterônoma que os meios de comunicação se encarregam de perpetuar. "A energia pulsional do Homo economicus então requerida ao Homo psycologicus é amor forçado, inculcado coercitivamente em direção a algo antes odiado" (idem, p. 144). Diante da desproporção flagrante entre o poder das instituições e a impotência do indivíduo, a resistência à socialização forçada exige forças sobre-humanas, cada vez mais raras em uma estrutura econômica que se encarrega de minar exatamente a capacidade individual de resistir (idem, p. 145).

\section{Semicultura na revista Nova Escola}

A manifestação dos elementos regressivos da semiformação por meio da indústria cultural, que ocorre de maneira eloqüente na maior parte das publicações e produtos televisivos e cinematográficos, adquire um caráter especialmente significativo no caso de uma publicação pedagógica destinada ao grande público docente. Trata-se da revista Nova Escola, publicação da Fundação Victor Civita, justificada pela proposta de "valorizar e qualificar o professor $d a$ Educação Básica em todo o Brasil', que desde sua origem, é distribuída gratuitamente a escolas públicas, e vendida, segundo seus editores, a preço de custo. Na medida em que alcança tiragens expressivas, que chegam a 700 mil exemplares mensais, é razoável supor que tratamos do único periódico educacional ao qual a maioria dos professores da rede pública tem acesso. Da mesma forma, podemos também supor que o sucesso da revista deve-se à popularização dos conteúdos, de maneira que a torne semelhante a outras revistas do Grupo Abril. Por meio de um vocabulário simplificado, acompanhado de ilustrações fartas, quase sempre a expor professores e alunos sorridentes, um pressuposto básico é exaustivamente repetido: os problemas educacionais sempre podem ser resolvidos, bastando para isso que cada um " $f a c ̧ a$ a sua parte".

Por vários motivos, a revista Nova Escola constitui-se em objeto de estudo que apresenta de maneira 
exemplar a configuração da semicultura na sociedade globalizada contemporânea. Seu modelo editorial apresenta-se como uma tradução, para termos próprios à educação, do mesmo modelo seguido pelas demais revistas de entretenimento do Grupo Abril. Sua fórmula consistiria, assim, em descaracterizar a categoria "professor" da especificidade que ela possui, reduzindo-a a mais um entre outros estereótipos da indústria cultural. Assim como para a adolescente vende-se Capricho, para a mulher madura vende-se Nova, para o macho vende-se Playboy, para o homem de negócios vende-se Exame, da mesma forma, para o professor, vende-se Nova Escola. Essas publicações, bem como outras, de grande tiragem, parecem obter popularidade e sucesso em termos comerciais por seguirem um modelo editorial baseado em estereotipias análogas àquelas apontadas por Adorno em sua análise da coluna astrológica do Los Angeles Times. Tratase, como definiu Adorno, de reiterar "as demandas que a sociedade impõe para o singular para que este funcione" (Horkheimer \& Adorno, 1971, p. 209). Enquadrado como mais um entre os estereótipos da sociedade de massas, o professor, ao lado da adolescente, da mulher madura, do macho, do homem de negócios etc., vê-se anulado como um sujeito universal capaz de pensar o todo. Desincumbido de sua especificidade, ao professor resta apenas o consumo distraído de fórmulas que o põem em sintonia com uma totalidade que assim permanece imune à crítica.

Em termos gerais, prevalece em Nova Escola uma visão operacional da realidade pedagógica, manifestada segundo dois aspectos principais.

1) Voluntarismo e estereotipia. Os problemas educacionais são reiteradamente reduzidos a questões a serem resolvidas individualmente pelo professor, $o$ qual é pressuposto como um ser dotado de inesgotável força de vontade, permanentemente disposto a se superar no cumprimento de sua missão. ${ }^{1}$ Esse tipo de

${ }^{1}$ A exaltação do voluntarismo evidencia-se no concurso anual "Prêmio Victor Civita - Professor nota 10", promovido pela Fundação Victor Civita. O concurso visa premiar experiências de boa abordagem parece baseado no modelo da auto-ajuda, pois reduz a complexidade e a materialidade dos problemas ao voluntarismo pessoal. Essa redução é determinada materialmente pelo modelo econômico neoliberal, desde suas origens no início dos anos de 1990. Ou seja, o lançamento de Nova Escola, ao coincidir com o recrudescimento de um modelo econômico fortemente inspirado na reprodução do capital via abertura dos mercados, indica uma forte sintonia com as premissas do Estado mínimo, uma vez que faz apologia da união da comunidade para a resolução dos problemas educacionais.

Os antagonismos próprios ao campo educacional, que refletem as contradições da própria sociedade, desaparecem na maior parte das reportagens e artigos da revista, prevalecendo uma visão operacional amparada na iniciativa pessoal como recurso suficiente para a resolução dos problemas pedagógicos. Os profissionais da área pedagógica são esvaziados de sua especificidade como possíveis agentes problematizadores das tensões sociais, e reduzidos exclusivamente à dimensão prática de seu ofício. Como a qualquer outro profissional, são recomendados exercícios e posturas para combater o estresse, sem que o fenômeno de exploração exaustiva do corpo e da mente seja remetido à dissonância entre as necessidades do indivíduo e os imperativos do capital. ${ }^{2}$ Escolas em que os Conselhos Escolares se mobilizam para arrecadar recursos não-públicos para a realização de reformas e aquisição de equipamentos são saudadas como exemplo de parceria bem-sucedida entre pais, comunidade e professores, sem que a precariedade implícita da relação entre escola pública e Estado, decorrente do modelo neoliberal do Estado mínimo, seja problematizada. ${ }^{3}$ Experiências bem-sucedidas e premiadas pela própria revista são exaustivamente

qualidade no ensino infantil e fundamental, oferecendo premiações em dinheiro e troféu similar ao Oscar da Academia de Cinema de Hollywood.

\footnotetext{
2 "Uma pausa para a ioga", Nova Escola, p. 22-29, jan./fev. 2006.

3 “Gestão”, Nova Escola, p. 33-41, nov. 2005.
} 
apresentadas com o objetivo de motivar o professor para a reprodução dos projetos por conta própria, entretanto, sem o acompanhamento de uma reflexão crítica sobre a grave crise de um contexto educacional no qual há a necessidade desse tipo de recurso.

A imagem estereotipada de um professor voluntarioso, decidido a resolver os problemas educacionais por conta própria, espelha o aspecto central analisado por Adorno em seu estudo sobre o fascismo: a conversão da individualidade em mero acessório da máquina social, sob o imperativo da retificação permanente do existente. O professor presumidamente voluntarioso de Nova Escola absorve os efeitos das demandas repressivas impostos pelo ritmo de acumulação do capital como um problema exclusivamente seu, a ser resolvido por meio de exercícios de ioga que aliviam o sofrimento físico e mental; sua atuação como cidadão restringe-se à mobilização da comunidade para compensar a atuação precária do Estado mínimo; carente de experiências bem-sucedidas que possam modelar sua prática e motivá-lo para a dureza da vida docente, encontra em Nova Escola premiações que talvez poderão mitigar suas frustrações.

2) Visão pragmática do conhecimento. Nova Escola manifesta claramente os traços regressivos que caracterizam a semiformação como "esfera do ressentimento". O conhecimento é rigorosamente expurgado de potenciais dialéticos que possam permitir o confronto entre ideais emancipadores e realidade imediata. No espírito da semiformação, a frustração perante as esperanças irrealizadas de um mundo livre e emancipado reverte o pensamento (que poderia permanecer fiel aos ideais traídos, insistindo na crítica negativa da realidade) em agente de perpetuação da existência alienada. Movendo-se rigorosamente no interior de códigos instrumentais de análise da realidade, o conhecimento adere a uma visão estritamente operacional da realidade pedagógica, recusando previamente outras perspectivas de abordagem que não estejam comprometidas com a reafirmação do status quo.

A relação entre professores e pais de alunos, que necessariamente deveria envolver um projeto de formação em que as expectativas imediatas dos pais pu- dessem ser confrontadas com ideais de formação transcendentes diante do existente, é despida de sua tensão intrínseca, sendo convertida em uma relação entre prestadores de serviço e clientes. Uma vez realizada essa redução, que implica ocultar do campo pedagógico justamente os antagonismos que podem fazer dele um campo de formação, a relação entre professores e pais transforma-se em oportunidade de convencimento por meio das ferramentas instrumentais do marketing. Essa operacionalização da realidade pedagógica permite, então, que Nova Escola transmita a seus leitores um enfoque que reduz a "gestão" escolar a um caráter exclusivamente prático, inspirado nos padrões adotados pelo departamento de recursos humanos da empresa capitalista. Oferece aos leitores "10 passos para se sair bem na primeira reunião de pais", reportagem de auto-ajuda que visa fornecer subsídios para "fisgar a família e transformá-la em grande aliada" (Nova Escola, p. 26-27, jan./fev. 2006). A assimilação dos referenciais do mercado capitalista para a reflexão pedagógica estende-se das ferramentas de "gestão" aos próprios temas abordados/a serem abordados em sala de aula. Assim, uma experiência realizada em uma escola com o objetivo de iniciar os estudantes no "empreendedorismo" é saudada como exemplo de perfeita adequação da escola às necessidades do mundo atual. Enfatizou-se neste caso a necessidade de adequação da escola às demandas competitivas do mundo do trabalho, que requerem "desenvolver nos alunos um conjunto de competências que possa torná-los capazes de tomar decisões, traçar planos e organizar os recursos necessários para chegar ao sucesso" (Nova Escola, p. 58-60, out. 2005). A ressemantização da terminologia pedagógica de modo que atenda às demandas do mercado capitalista consagra os conceitos do empreendedorismo como objetivos a serem assimilados por meio dos conteúdos, habilidades e competências a serem desenvolvidos. A adequação dos componentes curriculares aos imperativos do mercado introduzem, por exemplo, a simulação em sala de aula de uma "loja de doces", atividade que permite desenvolver "técnicas de negociação, compra e venda e manipulação de dinheiro", e de uma 
"feira de frutas", com o objetivo de desenvolver competências associadas à "definição de possíveis clientes; técnicas de comunicação e vendas; e identificação de concorrentes" (idem, ibidem). O pragmatismo pedagógico estende-se sutilmente na concepção instrumental do conhecimento, evidenciando-se em uma reportagem sobre novas invenções na área de nanotecnologia, justificada pelo fato de que "pesquisadores e homens de negócio prevêem muita novidade e muito lucro nos próximos anos" (Nova Escola, p. 35-38, nov. 2005).

Os potenciais dialéticos da educação como poder de negação da realidade imediata, mediante sua confrontação com os ideais iluministas de emancipação, são previamente neutralizados pelo enfoque operacional da realidade pedagógica, o qual se contenta com a perspectiva realista e antiutópica que reduz cada indivíduo a mero acessório da máquina social. Em sua recusa de transcendência ante a realidade estabelecida, o tipo de educação almejado por Nova Escola limita-se à perpetuação da semiformação como "esfera do ressentimento", como negação prévia de toda possibilidade formadora que possa ter como objetivo algo mais além da aceitação inflexível da instrumentalização da vida. Ao serem pressupostos como meros receptáculos de conselhos práticos, analogamente aos leitores de horóscopo e consumidores em geral das diversas publicações da indústria cultural, os professores são reduzidos a seres impotentes, incapazes de resistir à socialização forçada, sob pena da nãointegração. A sociedade, que é obra de homens que agem em condições materialmente determinadas, adquire, perante a totalidade de indivíduos subsumidos aos nichos de mercado cultural, uma dignidade metafísica tão duvidosa quanto aquela atribuída à totalidade astral. De maneira análoga aos artifícios empregados pelos produtores musicais, que fazem a escolha pela música pré-digerida parecer resultado da autonomia de escolha, também no caso de Nova Escola a complexidade dos problemas educacionais é reduzida a receitas imediatas que acenam com resultados garantidos àqueles que se esforçarem ao "convite constante a criticar-se a si mesmo e não às condições dadas" (Adorno, 1965, p. 209). Assim como fazem os produtores musicais, Nova Escola pensa antecipadamente os problemas pelos leitores, oferecendo suas soluções instrumentais como modelos a serem imitados ou aperfeiçoados por eles.

Entretanto, conforme salienta Adorno (1991), as massas não aceitariam o sacrifício permanente, não se sujeitariam à servidão voluntária se algo nelas próprias não desse acolhimento a tais apelos. Uma vez que a heteronomia não é meramente gerada de cima para baixo, pois atende a necessidades intensas de integração social que se converteram em uma segunda natureza do homem contemporâneo, cabe destacar que a sedução exercida por Nova Escola é tão ambígua quanto a própria indústria cultural. Ao adequar-se aos desejos de seu público, ela atende a necessidades efetivas deste, como poderá atestar qualquer pesquisa de opinião. Os professores realmente clamam pela combinação entre informação e entretenimento, pelas pílulas suaves de auto-ajuda que ilusoriamente possam aplacar a angústia provocada por poderes sociais que parecem tão ameaçadores quanto o eram, para o homem primitivo, os poderes da natureza. Mas, exatamente ao satisfazer desejos heterônomos, Nova Escola converte-se em produto cultural regressivo, pois se faz cúmplice de um estado de reificação que somente os educadores poderão superar.

\section{Referências bibliográficas}

ADORNO, Theodor W. Estudio cualitativo de las ideologias. In: ADORNO, Theodor W. et. al. La personalidad autoritaria. Buenos Aires: Proyección, 1965. p. 567-728.

Sobre música popular. In: COHN, Gabriel (Org.).

Theodor Adorno. São Paulo: Ática, 1986. p. 115-146 (col. Grandes Cientistas Sociais).

De la relación entre sociologia y psicologia. In:

ADORNO, Theodor W. Actualidad de la filosofia. Barcelona: Paidós, 1991. p. 135-204.

. Educação e emancipação. Trad. Wolfgang Leo Maar.

Rio de Janeiro: Paz e Terra, 1995.

HORKHEIMER, Max; ADORNO, Theodor W. Sociologica. Madrid: Taurus, 1971. 
Semicultura e educação

MARCUSE, Hebert. A ideologia da sociedade industrial. Trad. Giazone Rebuá. Rio de Janeiro: Zahar, 1969.

SINÉSIO FERRAZ BUENO, doutor em filosofia da educação pela Universidade de São Paulo (USP), é professor do Departamento de Filosofia da Universidade Estadual Paulista (UNESP) de Marília. Publicações recentes: Pedagogia sem sujeito (São Paulo: Anna Blume, 2003); Política contemporânea e sociedade unidimensional (Trans/form/ação, Revista de Filosofia, Marília, v. 27, n. 1, p. 39-50, 2004); Vida danificada e trote universitário (Educação em Revista, n. 6, p. 37-50, 2006). Pesquisa em andamento: "Semicultura e regressão no mundo contemporâneo". E-mail: sinesioferraz@yahoo.com.br

Recebido em outubro de 2006 Aprovado em fevereiro de 2007 